\title{
Tumor Microenvironment in Head and Neck Squamous Cell Carcinoma: A Focus on Tumor-Infiltrating Lymphocytes
}

\author{
Marzieh Norouzian, Sima Balouchi-Anaraki
}

Shiraz Institute for Cancer Research, Shiraz University of Medical Sciences, Shiraz, Iran.

\begin{abstract}
For more progress in head and neck squamous cell carcinoma (HNSCC) immuno-oncology, further understanding of interactions between tumor and immune system as well as factors in the tumor microenvironment is required. HNSCC is seriously infiltrated by lymphocytes but is known to be highly immunosuppressive. The aim of this review is to highlight the complexity of tumor microenvironment and tumor- immune cells interaction in the HNSCC, in order to improve understanding of tumorigenesis and disease progression in HNSCC patient and to provide valuable information about prognostic markers. The main goal of this review is to discuss the role of the tumor infiltrating lymphocytes in tumor progression, their cross-talk with other components of the tumor microenvironment as well as their roles in carcinogenesis, metastasis process, treatment, and prognosis in head and neck squamous cell carcinomas.
\end{abstract}

Keywords: HNSCC- tumor infiltrating lymphocytes- tumor microenvironment- lymphocytes- inflammation- hypoxia

Asian Pac J Cancer Biol, 4 (2), 19-26

\section{Introduction}

Head and neck squamous cell carcinoma (HNSCC) is a heterogeneous group of upper aerodigestive tract malignancies that accounts for $90 \%$ of all head and neck cancer cases. HNSCC is the sixth most common cancer by incidence, and a leading cause of cancer-related death [1]. Besides alcohol and smoking, human papillomavirus (HPV) has been recently regarded as a major etiological factor for a subgroup of HNSCC including oropharynx [2-5].

Despite the improvement of treatment regimens, the 5-year survival of HNSCC patients is only about $40-50 \%$ [6]. Tumor micrometastases to lymphovascular and/or perineural are associated with increased recurrence rate [7]. Accordingly, the development of new treatment modalities and establishing accurate prognostic markers is always demand.

Recently it has been shown that tumor aggressiveness and therapy resistance are extremely influenced by the interactions between tumor cells and their surrounding microenvironment [8-9].

HNSCC tumors are highly infiltrated by different types of immune cells which are considered as important
Submission Date: 05/01/2019 Acceptance Date: 07/01/2019

elements of TME for predicting clinical outcome of the disease [10-13]. Although the presence of certain immune cells in the tumor microenvironment (TME) is related to favorable outcome [14], some indications propose that antitumor immune responses are impaired in HNSCC and are related to disease progression [15].

Different aspects of the HNSCC tumor microenvironment including the influence of tumor cells-immune cells interactions on the activation and regulation of cell-mediated immune responses have remained to be cleared. Comprehensive understanding of the interactions between immune cells and tumor microenvironment components in HNSCC may lead to the development of new cancer therapy modalities to improve immune responses against this highly mortal malignancy.

The purpose of this article is to review the main components of the tumor microenvironment in HNSCC, their cross talk and the effect of metabolic changes on the structure/ function of the tumor microenvironment.

An overview of the tumor microenvironment in HNSCC

The tumor microenvironment is a complex and dynamic network of cellular and non-cellular components

Corresponding Author:

Dr. Marzieh Norouzian

Shiraz Institute for Cancer Research, Shiraz University of Medical Sciences, Shiraz, Iran.

Email: marzieh.norouzi@gmail.com 
including malignant cells, cancer-associated fibroblasts, endothelial cells, infiltrating immune cells, and secretory mediators such as exosomes which contribute to the establishment of complex crosstalk with the tumor entity [16-17]. It has been shown that some tumor microenvironment-associated factors such as hypoxia [18], inflammation and angiogenesis [19] may influence the infiltration of lymphocytes to HNSCC and play pivotal roles in the tumor development, invasion and metastasis. Environmental factors such as tobacco or alcohol have been shown to influence the progression of HNSCC through the induction of genetic alterations, which in turn result in the suppression of immune system, the transformation of stromal cells and induction of chronic inflammation [8-9].

As a highly immunomodulatory tumor, HNSCC takes advantage of genetic and environmental mechanisms such as the selection of poorly immunogenic cancer cell subsets, production of proinflammatory and immunosuppressive cytokines, secretion of exosomes, induction of immunosuppressive immune cells and expression of immune checkpoint pathway molecules [20-24]. The mechanism by which tumor infiltrating cells become suppressed in the tumor microenvironment is not completely understood, though it has been associated with the presence of immunosuppressive cells such as regulatory $\mathrm{T}$ cells and myeloid-derived suppressor cells (MDSCs) [25-26]. Recent studies have also shown that the release of tumor-derived exosomes is related to the immunosuppression in the tumor microenvironment [27].

Exosomes are small membranous vesicles originated from endocytic compartments which are released to the extracellular spaces. Exosomes have recently been identified in several human malignancies including melanoma [28], Glioblastoma [29], colorectal cancer [30] and Hepatocellular cancer [31]. Tumor-derived exosomes are composed of different proteins and microRNAs and play a key role in the cross-communication between tumors and the cells of the immune system, promoting the immune evasion of tumors [23-32-35]. The presence of Exosomes, in HNSCC and some other tumors, has been correlated with advanced tumor stages. Exosomes have been considered as main contributors responsible for progression, metastasis, survival, immune regulation and other invasive characteristics of tumors which function through communication with cells in the tumor microenvironment. Although the underlying mechanisms of the production of exosomes are yet to be explored, it has been shown that exosomes act as carriers for immunosuppressive molecules delivering them to the target immune cells. Recent studies have shown that increased levels of immunomodulating PD-L1+exosomes isolated from blood samples of HNSCC patients are linked to tumor progression and immune suppression [36-37].

It has been shown that exosomes have different morphology and molecular features in oral cancer patients compared to healthy individuals, which can be used as an early diagnostic marker for identifying malignant changes in high-risk cases [38]. In the tumor microenvironment, exosomes through interaction with hypoxia, inflammation, and angiogenesis associated elements can influence the incidence and progression of tumors. In hypoxic microenvironment tumor cells stimulate generate miR-21-rich exosomes that are delivered to normoxic cells and promoted prometastatic behaviors. Moreover, exosomes derived from hypoxic oral squamous cell carcinoma (OSCC) cells increase the migration and invasion of tumor cells in a HIF- $1 \alpha$ and HIF- $2 \alpha$-dependent manner [39].

The effect of Hypoxia, inflammation in head and neck squamous cell carcinoma microenvironment on tumor infiltrating lymphocytes

In many types of tumors including HNSCC, the inflamed microenvironment in combination with low oxygen concentration is ideal factors which contribute to tumorigenesis and angiogenesis through immune cell dysregulation such as apoptosis of cytotoxic T cells and activation of suppressor T cells [40-42]. Hypoxia inducible factor (HIF) is a transcription factor which is induced following hypoxia in the tumor microenvironment. HIF acts as a regulator of immune cells effector function through an effect on their cytokine production ability, their survival, and apoptosis [43]. It was shown that high PD-L1 expression by the tumor cells under hypoxic conditions, which induces tumor resistance into CD8+ T cells toxic agents [44]. In addition, HIFs display strong signaling which results in the switch of inflammatory responses to a pro-tumorigenic state by recruiting immune cells and changing their effector functions to suppress antitumor immune responses. Higher expression of HIF is reported as a negative prognosticator in patients with HNSCC [45]. It has been reported that tumor infiltrating lymphocytes in HNSCC, which encountered low oxygen concentration, reduce production level of cytokines and granzyme due to the hindrance of Kv1.3 channels [46].

Inflammation, as the second factor which contributes to tumor growth, has been shown to closely relate with HNSCC development. In a murine model of HNSCC it has been observed that in premalignant stage, the level of Th1, Tc1, and Th17 increased in comparison with a control group and HNSCC-bearing mice, however, the frequency of regulatory $\mathrm{T}$ cells was higher in HNSCC-bearing mice [47]. Another study showed that in established HNSCC, lower levels of proinflammatory agents were detected including CCL5, MCP-1, G-CSF, and PGE2 as compared with lesions of premalignant state [48]. These two above mentioned studies suggest the premalignant microenvironment to be more immune stimulatory than the microenvironment of an established HNSCC. However, it remains uncertain if inflammation at the primary tumor site represents a beneficial manifestation of a patient's immune response to cancer in the tumor microenvironment or actually is a carcinogenic response that enhances tumor progression through the elaboration of regulatory cytokines such as IL-6, IL-10, and IL-17 [49-51]. Further investigations were needed in order to understand the multilateral effects of 
the inflammation at the primary state of the tumor.

\section{TILs in HNSCC}

Tumor-infiltrating lymphocytes (TILs) are important predictors of tumor biology and outcome. Several studies showed the presence of TILs in different tumors and functional subsets are a favorable prognostic factor for treatment and linked with patients' clinical outcomes [52-53].

In HNSCCs, better response to definitive chemo radiotherapy has been reported in cases with a higher number of TILs [54-55], and better outcomes were reported following surgery with adjuvant therapy [56].

Presence of TILs in HNSCC indicates that this cancer can be considered as immunogenic cancer. However, the antitumor immune responses are affected by functional defects or apoptosis of both circulating and tumor-infiltrating T-cells [15-57-61]. Moreover, numbers of TILs, their function, and location in the HNSCC microenvironment may significantly vary independent ly to the site and size of tumors. For example, oropharyngeal tumors contain higher levels of T-cell infiltration, compared to tumors at other sites of the head and neck [62-63].

Studies have shown that different subsets of lymphocytes have altered or even opposite functions in the tumor microenvironment. Indeed, it has been founded that high $\mathrm{CD} 8+\mathrm{T}$ cell infiltration associated with a better prognostic value and outcome in HNSCC [64]. however, the role of a wide range of CD4+ cell subsets with different functions in the tumor microenvironment and their prognostic role remains to be elucidated [65-66].

\section{T cells}

$\mathrm{T}$ cells are one of the important factors that organize the immune system to check and remove malignant cells in favor of immune surveillance [67-68]. In several malignancies such as colorectal and ovarian cancer, high infiltration of CD8+ Cytotoxic T cells are positively correlated with prognosis and favorable outcome compared to no infiltration [69-73]. Also, it has been reported patients with HNSCC whose tumor was extremely infiltrated by CD8+ T cells have a significantly better outcome compared to patients with slight or no infiltration of CD8+ T cells [44-55-56-74-75]. However, in the study of oral cavity tumors, high level of CD8+ TILs has shown no significant prognostic value [76-78] or was positively correlated with tumor recurrence [79]. These results could be a consequence of different biological behavior oral cavity with a high grade of local invasion and metastasis to the cervical lymph nodes [80].

In addition, some evidence showed differences in prognostic significance of TILs depending on the tumor compartments (tumor epithelium, tumor stroma). For instance, in HPV-positive oropharyngeal squamous patients, stromal infiltration of CD8 T cells was associated with favorable outcome [81]. Other studies suggested that a high level of CD8+ cells in tumor epithelium predicted a better clinical outcome [64]. However, in a study conducted by Balermpas et. al the differences in the prognostic value of stromal and epithelial CD8+ cells has not been reported [56]. It seems that more studies are needed to shed light on the role of CD8+ cells in different compartments of the tumor and their impact on cancer prognosis.

However, the advantage of CD4+ T cell infiltration in the tumor microenvironment is slightly controversial. At first, CD4+T cells were found as a positive prognostic factor in pancreatic and esophageal squamous cell carcinoma. In HNSCCs, studies suggested that high levels of tumor-infiltrating CD4+CD69+ T cells were positively correlated with more favorable prognosis [76-82]. In contrast, other studies proposed CD4+T cells as a poor prognostic predictor, especially in oral cavity cancer [83]. Heterogeneity of the CD4+T cell population and its characteristic cytokine profiles may explain these contradictory results [84].

In the microenvironment of many solid tumors, such as hepatocellular, breast and lung cancer, a high ratio of cytotoxic CD8+ T lymphocytes/Treg cells was reported as a good prognostic factor [14]. However, the prognostic value of Treg cells seems to be different between types of cancer. Previous studies suggested that in HNSCC high immune-suppressing Treg cells number was associated with better prognosis and clinical outcome [85]. In a study on the tumor specimens of oral cavity cancer patients, low stromal cytotoxic CD8+ T-lymphocyte counts and the high number of stromal Treg cells were associated with low survival [86]. Some studies on oropharynx cancer showed different results compared with other types of head and neck cancers [87-89]. The data show that in oropharyngeal cancer high levels of cytotoxic CD8+ $\mathrm{T}$ cells could be considered as a positive prognostic factor, but the influence of high rate of $\mathrm{T}$ regulatory cells is controversial. According to this, more studies are required to confirm the prognostic value of the $\mathrm{CD} 8+\mathrm{T}$ lymphocytes/Treg cells ratio in HNSCC.

\section{$B$ cells}

Most former studies have focused on cytotoxic $\mathrm{T}$ cells that exhibit the highest antitumor activity among other immune cells. Recently B cells, another important fraction of TILs, have been identified as the important predictor of disease outcome [90-92]. Evidence shows that $\mathrm{B}$ cells can promote or inhibit the progression of tumors through producing antibodies against the tumor antigens, acting as APC and secreting numerous cytokines. Several factors such as tumor type and the subset of B cell influence the role of B cells in the support or prevention of tumor growth.

Most previous studies in HNSCC have investigated $\mathrm{B}$ cells by immunohistochemistry method that prognostic effect of tumor-infiltrating CD20+ B cells was described on the outcome [93-94]. Distel et.al showed a favorable outcome correlated in the high percentage of B-lymphocytes in patients with early-stage HNSCC, in contrast to an inverse association in the advanced stage. These results suggest that there is phenotypic and functional plasticity of B cells during the course of disease progression [95]. However knowledge about the different B cell subsets in 
tumor microenvironment of HNSCC is in short, recent study of flow cytometric analysis of tumor-infiltrating B cell subpopulations including activated $\left(\mathrm{CD}^{+} 6^{+}\right)$, antigen-presenting $\left(\mathrm{CD} 86^{+} \mathrm{CD} 21^{-}\right)$, memory $\left(\operatorname{IgD}^{-} \mathrm{CD} 27^{+}\right)$ in HNSCC demonstrated significant difference in the frequencies of different $B$ cell subsets in tumor microenvironment of patients with $\mathrm{HPV}+$ compared to HPV- HNSCC although it did not show any relation to disease stage [96].

Besides, in some few studies infiltration of HNSCC by regulatory $\mathrm{B}$ cells was investigated. Lechner et. al observed the high infiltration of CD $24^{\text {hi }} \mathrm{CD} 38^{\text {hi }}$ and $\mathrm{CD} 25^{\text {hi }}$ regulatory $\mathrm{B}$ cells in tumor tissue of HNSCC compared to peripheral blood of patients and healthy controls [97]. However, the significance of regulatory B cells in immunity against tumor remains to be elusive in humans. In tongue squamous cell carcinoma has been indicated that CD19+IL-10+ regulatory B cells affected the survival of patients by inducing Tregs through secretion of IL-10 [94]. Still, further investigation is required to clarify in more detail function and phenotype of regulatory B cell subsets in the tumor microenvironment of HNSCC.

Immune-inflamed cancer phenotype and benefit to immunotherapy

Like other solid tumors, HNSCC shows two main immunophenotypes: i) inflamed tumor type with a rich $\mathrm{T}$ cell infiltrate, a type 1 interferon signature, and various chemokine profiles, ii) non-inflamed type without these structures [98]. The structure of $\mathrm{T}$ cell- inflamed tumor indicated a previous antitumor immune response might have existed that was ineffective due to the obstruction of tumor penetration through stroma or by the retention of immune cells in the stroma [99]. Understanding the resistance mechanisms in both $\mathrm{T}$ cell-inflamed and non-inflamed tumors are essential for overcoming treatment failure and increasing the response rate of patients to current immunotherapy. In addition, the modulation of the tumor microenvironment has become increasingly an issue in the field of immunization, and studies on immune checkpoint mediated immunosuppression and cancer immunotherapy have peaked the safety of cancer treatment [100].

The new mAbs approved by the US Food and Drug Administration (FDA) for HNSCC patients are anti-PD-1 mAbs nivolumab and pembrolizumab [101], in addition to cetuximab, a mAb against epidermal growth factor receptor (EGFR) [102]. However, most do not benefit from anti-PD1 therapy. Understanding of Inhibitory checkpoint receptor mechanisms may help the clinician to correctly select certain immunotherapy options for specific patients. Some immune checkpoints such as LAG3 and TIM3have become attractive goals for prevailing to the resistance of tumors with an inflamed phenotype including melanoma, NSCLC, and HNSCC [103]. Due to the potentially severe toxicity and high costs of immune checkpoint inhibitors, the search for predictive biomarkers that can target immune cell infiltration is highly demanded. The immune cell subsets and their position in the TME could affect the prognosis and prediction of response to Immune-checkpoint inhibitors therapy. Besides, Most clinical trials in both recurrent and metastatic HNSCC patients indicated that factors other than PD-L1 expression, including tumor-immune cell infiltration, tumor mutational burden and human papillomavirus (HPV) may contribute to the patients' response to treatment [63-104].

Taken together, a better understanding of the tumor-immune cell cross talk and the resistance mechanisms in both $\mathrm{T}$ cell-inflamed and non-inflamed tumors, affect the successfulness of immunotherapy for overcoming resistance to available therapies and designing novel immunotherapies in order to increase patients benefit from immunotherapy.

In conclusion, HNSCC tumor microenvironment is composed of stromal fibroblasts, vasculature, immune cells, cytokines, and hypoxia which play a supportive role in the initiation, progression, and metastasis of the tumor. In HNSCC, there is a complexity in tumor-immune system interactions which are mainly dictated by the tumor microenvironment. A rational approach to further clinical investigation requires a deeper understanding of the interaction of the immune system with the tumor microenvironment. As more is discovered about the interaction of the immune system with HNSCC tumors in the development of the disease and in the mechanisms of tumor resistance; the opportunity for earlier intervention may also become possible.

\section{References}

1. Marur S, Forastiere AA. Head and Neck Squamous Cell Carcinoma: Update on Epidemiology, Diagnosis, and Treatment. Mayo Clinic proceedings. 2016;91(3):386-96.

2. Ang KK, Harris J, Wheeler R, Weber R, Rosenthal DI, Nguyen-Tan PF, et al. Human papillomavirus and survival of patients with oropharyngeal cancer. The New England journal of medicine. 2010;363(1):24-35.

3. Posner MR, Lorch JH, Goloubeva O, Tan M, Schumaker LM, Sarlis NJ, et al. Survival and human papillomavirus in oropharynx cancer in TAX 324: a subset analysis from an international phase III trial. Annals of oncology : official journal of the European Society for Medical Oncology. 2011;22(5):1071-7.

4. Rischin D, Young RJ, Fisher R, Fox SB, Le QT, Peters LJ, et al. Prognostic significance of p16INK4A and human papillomavirus in patients with oropharyngeal cancer treated on TROG 02.02 phase III trial. Journal of clinical oncology : official journal of the American Society of Clinical Oncology. 2010;28(27):4142-8.

5. Zandberg DP, Bhargava R, Badin S, Cullen KJ. The role of human papillomavirus in nongenital cancers. CA: a cancer journal for clinicians. 2013;63(1):57-81.

6. Wang WL, Lee CT, Lee YC, Hwang TZ, Wang CC, Hwang JC, et al. Risk factors for developing synchronous esophageal neoplasia in patients with head and neck cancer. Head \& neck. 2011;33(1):77-81.

7. Huang TY, Hsu LP, Wen YH, Huang TT, Chou YF, Lee CF, et al. Predictors of locoregional recurrence in early stage oral cavity cancer with free surgical margins. Oral oncology. 2010;46(1):49-55.

8. Curry JM, Sprandio J, Cognetti D, Luginbuhl A, Bar-ad V, Pribitkin E, et al. Tumor microenvironment in head and 
neck squamous cell carcinoma. Seminars in oncology. 2014;41(2):217-34.

9. Hadrup S, Donia M, Thor Straten P. Effector CD4 and CD8 T cells and their role in the tumor microenvironment. Cancer microenvironment : official journal of the International Cancer Microenvironment Society. 2013;6(2):123-33.

10. Aarstad HJ, Vintermyr OK, Ulvestad E, Aarstad HH, Kross KW, Heimdal JH. Peripheral blood monocyte and T-lymphocyte activation levels at diagnosis predict longterm survival in head and neck squamous cell carcinoma patients. APMIS : acta pathologica, microbiologica, et immunologica Scandinavica. 2015;123(4):305-14.

11. Hartmann E, Wollenberg B, Rothenfusser S, Wagner M, Wellisch D, Mack B, et al. Identification and functional analysis of tumor-infiltrating plasmacytoid dendritic cells in head and neck cancer. Cancer research. 2003;63(19):647887.

12. Pries R, Wollenberg B. Cytokines in head and neck cancer. Cytokine \& growth factor reviews. 2006;17(3):141-6.

13. Veltri RW, Rodman SM, Maxim PE, Baseler MW, Sprinkle PM. Immune complexes, serum proteins, cell-mediated immunity, and immune regulation in patients with squamous cell carcinoma of the head and neck. Cancer. 1986;57(12):2295-308.

14. Wallis SP, Stafford ND, Greenman J. Clinical relevance of immune parameters in the tumor microenvironment of head and neck cancers. Head \& neck. 2015;37(3):449-59.

15. Whiteside TL. Down-regulation of zeta-chain expression in T cells: a biomarker of prognosis in cancer? Cancer immunology, immunotherapy : CII. 2004;53(10):865-78.

16. Mittal D, Gubin MM, Schreiber RD, Smyth MJ. New insights into cancer immunoediting and its three component phases-elimination, equilibrium and escape. Current opinion in immunology. 2014;27:16-25.

17. Schreiber RD, Old LJ, Smyth MJ. Cancer immunoediting: integrating immunity's roles in cancer suppression and promotion. Science. 2011;331(6024):1565-70.

18. Semenza GL. The hypoxic tumor microenvironment: A driving force for breast cancer progression. Biochimica et biophysica acta. 2016;1863(3):382-91.

19. Lee E, Pandey NB, Popel AS. Crosstalk between cancer cells and blood endothelial and lymphatic endothelial cells in tumour and organ microenvironment. Expert reviews in molecular medicine. 2015;17:e3.

20. Duray A, Demoulin S, Hubert P, Delvenne P, Saussez S. Immune suppression in head and neck cancers: a review. Clinical \& developmental immunology. 2010;2010:701657.

21. Meissner M, Reichert TE, Kunkel M, Gooding W, Whiteside TL, Ferrone S, et al. Defects in the human leukocyte antigen class I antigen processing machinery in head and neck squamous cell carcinoma: association with clinical outcome. Clinical cancer research : an official journal of the American Association for Cancer Research. 2005;11(7):2552-60.

22. Young MR. Protective mechanisms of head and neck squamous cell carcinomas from immune assault. Head \& neck. 2006;28(5):462-70.

23. Bergmann C, Strauss L, Wieckowski E, Czystowska M, Albers A, Wang Y, et al. Tumor-derived microvesicles in sera of patients with head and neck cancer and their role in tumor progression. Head \& neck. 2009;31(3):371-80.

24. Kim JW, Wieckowski E, Taylor DD, Reichert TE, Watkins S, Whiteside TL. Fas ligand-positive membranous vesicles isolated from sera of patients with oral cancer induce apoptosis of activated $\mathrm{T}$ lymphocytes. Clinical cancer research : an official journal of the American Association for Cancer Research. 2005;11(3):1010-20.
25. Facciabene A, Motz GT, Coukos G. T-regulatory cells: key players in tumor immune escape and angiogenesis. Cancer research. 2012;72(9):2162-71.

26. Ruffell B, Affara NI, Coussens LM. Differential macrophage programming in the tumor microenvironment. Trends in immunology. 2012;33(3):119-26.

27. Zhang HG, Grizzle WE. Exosomes and cancer: a newly described pathway of immune suppression. Clinical cancer research : an official journal of the American Association for Cancer Research. 2011;17(5):959-64.

28. Pfeffer SR, Grossmann KF, Cassidy PB, Yang CH, Fan M, Kopelovich L, et al. Detection of Exosomal miRNAs in the Plasma of Melanoma Patients. Journal of clinical medicine. 2015;4(12):2012-27.

29. Skog J, Wurdinger T, van Rijn S, Meijer DH, Gainche $\mathrm{L}$, Sena-Esteves M, et al. Glioblastoma microvesicles transport RNA and proteins that promote tumour growth and provide diagnostic biomarkers. Nature cell biology. 2008;10(12):1470-6.

30. Wang X, Ding X, Nan L, Wang Y, Wang J, Yan Z, et al. Investigation of the roles of exosomes in colorectal cancer liver metastasis. Oncology reports. 2015;33(5):2445-53.

31. Sohn W, Kim J, Kang SH, Yang SR, Cho JY, Cho HC, et al. Serum exosomal microRNAs as novel biomarkers for hepatocellular carcinoma. Experimental \& molecular medicine. 2015;47:e184.

32. Abusamra AJ, Zhong Z, Zheng X, Li M, Ichim TE, Chin $\mathrm{JL}$, et al. Tumor exosomes expressing Fas ligand mediate CD8+ T-cell apoptosis. Blood cells, molecules \& diseases. 2005;35(2):169-73.

33. Huber V, Fais S, Iero M, Lugini L, Canese P, Squarcina P, et al. Human colorectal cancer cells induce T-cell death through release of proapoptotic microvesicles: role in immune escape. Gastroenterology. 2005;128(7):1796-804.

34. Martinez-Lorenzo MJ, Anel A, Alava MA, Pineiro A, Naval $\mathrm{J}$, Lasierra $\mathrm{P}$, et al. The human melanoma cell line MelJuSo secretes bioactive FasL and APO2L/TRAIL on the surface of microvesicles. Possible contribution to tumor counterattack. Experimental cell research. 2004;295(2):315-29.

35. Qu JL, Qu XJ, Qu JL, Qu XJ, Zhao MF, Teng YE, et al. The role of cbl family of ubiquitin ligases in gastric cancer exosome-induced apoptosis of Jurkat T cells. Acta oncologica. 2009;48(8):1173-80.

36. Ludwig S, Floros T, Theodoraki MN, Hong CS, Jackson EK, Lang S, et al. Suppression of Lymphocyte Functions by Plasma Exosomes Correlates with Disease Activity in Patients with Head and Neck Cancer. Clinical cancer research : an official journal of the American Association for Cancer Research. 2017;23(16):4843-54.

37. Theodoraki MN, Yerneni SS, Hoffmann TK, Gooding WE, Whiteside TL. Clinical Significance of PD-L1(+) Exosomes in Plasma of Head and Neck Cancer Patients. Clinical cancer research : an official journal of the American Association for Cancer Research. 2018;24(4):896-905.

38. Zlotogorski-Hurvitz A, Dayan D, Chaushu G, Salo T, Vered M. Morphological and molecular features of oral fluid-derived exosomes: oral cancer patients versus healthy individuals. Journal of cancer research and clinical oncology. 2016;142(1):101-10.

39. Li L, Li C, Wang S, Wang Z, Jiang J, Wang W, et al. Exosomes Derived from Hypoxic Oral Squamous Cell Carcinoma Cells Deliver miR-21 to Normoxic Cells to Elicit a Prometastatic Phenotype. Cancer research. 2016;76(7):1770-80.

40. Brizel DM, Sibley GS, Prosnitz LR, Scher RL, Dewhirst MW. Tumor hypoxia adversely affects the prognosis of carcinoma of the head and neck. International journal of 
radiation oncology, biology, physics. 1997;38(2):285-9.

41. Han JY, Oh SH, Morgillo F, Myers JN, Kim E, Hong WK, et al. Hypoxia-inducible factor 1alpha and antiangiogenic activity of farnesyltransferase inhibitor SCH66336 in human aerodigestive tract cancer. J Natl Cancer Inst. 2005;97(17):1272-86.

42. Semenza GL. Hypoxia-inducible factors: mediators of cancer progression and targets for cancer therapy. Trends Pharmacol Sci. 2012;33(4):207-14.

43. Lukashev D, Klebanov B, Kojima H, Grinberg A, Ohta A, Berenfeld L, et al. Cutting edge: hypoxia-inducible factor 1alpha and its activation-inducible short isoform I.1 negatively regulate functions of $\mathrm{CD} 4+$ and $\mathrm{CD} 8+\mathrm{T}$ lymphocytes. Journal of immunology. 2006;177(8):4962-5.

44. Barsoum IB, Koti M, Siemens DR, Graham CH. Mechanisms of hypoxia-mediated immune escape in cancer. Cancer research. 2014;74(24):7185-90.

45. Eckert AW, Schutze A, Lautner MH, Taubert H, Schubert J, Bilkenroth U. HIF-1alpha is a prognostic marker in oral squamous cell carcinomas. The International journal of biological markers. 2010;25(2):87-92.

46. Chimote AA, Hajdu P, Sfyris AM, Casper KA, Conforti L. Hypoxic tumor microenvironment of head and neck cancers downregulates Kv1. 3 channels in tumor infiltrating lymphocytes. Am Assoc Immnol; 2016.

47. De Costa AM, Schuyler CA, Walker DD, Young MR. Characterization of the evolution of immune phenotype during the development and progression of squamous cell carcinoma of the head and neck. Cancer immunology, immunotherapy : CII. 2012;61(6):927-39.

48. Johnson SD, De Costa AM, Young MR. Effect of the premalignant and tumor microenvironment on immune cell cytokine production in head and neck cancer. Cancers. 2014;6(2):756-70.

49. Duffy SA, Taylor JM, Terrell JE, Islam M, Li Y, Fowler KE, et al. Interleukin-6 predicts recurrence and survival among head and neck cancer patients. Cancer. 2008;113(4):750-7.

50. Lee JJ, Chang YL, Lai WL, Ko JY, Kuo MY, Chiang CP, et al. Increased prevalence of interleukin-17-producing CD4(+) tumor infiltrating lymphocytes in human oral squamous cell carcinoma. Head \& neck. 2011;33(9):1301-8.

51. Strauss L, Bergmann C, Szczepanski M, Gooding W, Johnson JT, Whiteside TL. A unique subset of CD4+CD25highFoxp3+ T cells secreting interleukin-10 and transforming growth factor-betal mediates suppression in the tumor microenvironment. Clinical cancer research : an official journal of the American Association for Cancer Research. 2007;13(15 Pt 1):4345-54.

52. Wolf GT, Hudson JL, Peterson KA, Miller HL, McClatchey KD. Lymphocyte subpopulations infiltrating squamous carcinomas of the head and neck: correlations with extent of tumor and prognosis. Otolaryngology--head and neck surgery : official journal of American Academy of OtolaryngologyHead and Neck Surgery. 1986;95(2):142-52.

53. Gooden MJ, de Bock GH, Leffers N, Daemen T, Nijman HW. The prognostic influence of tumour-infiltrating lymphocytes in cancer: a systematic review with meta-analysis. British journal of cancer. 2011;105(1):93-103.

54. Balermpas P, Michel Y, Wagenblast J, Seitz O, Weiss C, Rodel F, et al. Tumour-infiltrating lymphocytes predict response to definitive chemoradiotherapy in head and neck cancer. British journal of cancer. 2014;110(2):501-9.

55. Nasman A, Romanitan M, Nordfors C, Grun N, Johansson H, Hammarstedt L, et al. Tumor infiltrating CD8+ and Foxp3+ lymphocytes correlate to clinical outcome and human papillomavirus (HPV) status in tonsillar cancer. PloS one. 2012;7(6):e38711.

56. Balermpas P, Rodel F, Rodel C, Krause M, Linge A, Lohaus $\mathrm{F}$, et al. CD8+ tumour-infiltrating lymphocytes in relation to HPV status and clinical outcome in patients with head and neck cancer after postoperative chemoradiotherapy: A multicentre study of the German cancer consortium radiation oncology group (DKTK-ROG). International journal of cancer. 2016;138(1):171-81.

57. Albers A, Abe K, Hunt J, Wang J, Lopez-Albaitero A, Schaefer $\mathrm{C}$, et al. Antitumor activity of human papillomavirus type 16 E7-specific $T$ cells against virally infected squamous cell carcinoma of the head and neck. Cancer research. 2005;65(23):11146-55.

58. Ferris RL, Hunt JL, Ferrone S. Human leukocyte antigen (HLA) class I defects in head and neck cancer: molecular mechanisms and clinical significance. Immunologic research. 2005;33(2):113-33.

59. Hathaway B, Landsittel DP, Gooding W, Whiteside TL, Grandis JR, Siegfried JM, et al. Multiplexed analysis of serum cytokines as biomarkers in squamous cell carcinoma of the head and neck patients. The Laryngoscope. 2005;115(3):522-7.

60. Hoffmann TK, Bier H, Whiteside TL. Targeting the immune system: novel therapeutic approaches in squamous cell carcinoma of the head and neck. Cancer immunology, immunotherapy : CII. 2004;53(12):1055-67.

61. Lopez-Albaitero A, Nayak JV, Ogino T, Machandia A, Gooding W, DeLeo AB, et al. Role of antigen-processing machinery in the in vitro resistance of squamous cell carcinoma of the head and neck cells to recognition by CTL. Journal of immunology. 2006;176(6):3402-9.

62. Green VL, Michno A, Stafford ND, Greenman J. Increased prevalence of tumour infiltrating immune cells in oropharyngeal tumours in comparison to other subsites: relationship to peripheral immunity. Cancer immunology, immunotherapy : CII. 2013;62(5):863-73.

63. Mandal R, Senbabaoglu Y, Desrichard A, Havel JJ, Dalin MG, Riaz N, et al. The head and neck cancer immune landscape and its immunotherapeutic implications. JCI insight. 2016;1(17):e89829.

64. de Ruiter EJ, Ooft ML, Devriese LA, Willems SM. The prognostic role of tumor infiltrating T-lymphocytes in squamous cell carcinoma of the head and neck: A systematic review and meta-analysis. Oncoimmunology. 2017;6(11):e1356148.

65. Kim HJ, Cantor H. CD4 T-cell subsets and tumor immunity: the helpful and the not-so-helpful. Cancer immunology research. 2014;2(2):91-8.

66. Nishimura T, Iwakabe K, Sekimoto M, Ohmi Y, Yahata T, Nakui M, et al. Distinct role of antigen-specific T helper type 1 (Th1) and Th2 cells in tumor eradication in vivo. The Journal of experimental medicine. 1999;190(5):617-27.

67. Gannot G, Gannot I, Vered H, Buchner A, Keisari Y. Increase in immune cell infiltration with progression of oral epithelium from hyperkeratosis to dysplasia and carcinoma. British journal of cancer. 2002;86(9):1444-8.

68. Lu SL, Reh D, Li AG, Woods J, Corless CL, Kulesz-Martin $\mathrm{M}$, et al. Overexpression of transforming growth factor betal in head and neck epithelia results in inflammation, angiogenesis, and epithelial hyperproliferation. Cancer research. 2004;64(13):4405-10.

69. Fukunaga A, Miyamoto M, Cho Y, Murakami S, Kawarada Y, Oshikiri T, et al. CD8+ tumor-infiltrating lymphocytes together with CD4+ tumor-infiltrating lymphocytes and dendritic cells improve the prognosis of patients with pancreatic adenocarcinoma. Pancreas. 2004;28(1):e26-31. 
70. Galon J, Costes A, Sanchez-Cabo F, Kirilovsky A, Mlecnik $\mathrm{B}$, Lagorce-Pages $\mathrm{C}$, et al. Type, density, and location of immune cells within human colorectal tumors predict clinical outcome. Science. 2006;313(5795):1960-4.

71. Kawai O, Ishii G, Kubota K, Murata Y, Naito Y, Mizuno $\mathrm{T}$, et al. Predominant infiltration of macrophages and CD8(+) T Cells in cancer nests is a significant predictor of survival in stage IV nonsmall cell lung cancer. Cancer. 2008;113(6):1387-95.

72. Nakano O, Sato M, Naito Y, Suzuki K, Orikasa S, Aizawa $\mathrm{M}$, et al. Proliferative activity of intratumoral CD8(+) T-lymphocytes as a prognostic factor in human renal cell carcinoma: clinicopathologic demonstration of antitumor immunity. Cancer research. 2001;61(13):5132-6.

73. Sato E, Olson SH, Ahn J, Bundy B, Nishikawa H, Qian F, et al. Intraepithelial CD8+ tumor-infiltrating lymphocytes and a high $\mathrm{CD} 8+/$ regulatory $\mathrm{T}$ cell ratio are associated with favorable prognosis in ovarian cancer. Proceedings of the National Academy of Sciences of the United States of America. 2005;102(51):18538-43.

74. Nordfors C, Grun N, Tertipis N, Ahrlund-Richter A, Haeggblom L, Sivars L, et al. CD8+ and CD4+ tumour infiltrating lymphocytes in relation to human papillomavirus status and clinical outcome in tonsillar and base of tongue squamous cell carcinoma. European journal of cancer. 2013;49(11):2522-30.

75. Pretscher D, Distel LV, Grabenbauer GG, Wittlinger M, Buettner M, Niedobitek G. Distribution of immune cells in head and neck cancer: CD8+ T-cells and CD20+ B-cells in metastatic lymph nodes are associated with favourable outcome in patients with oro- and hypopharyngeal carcinoma. BMC cancer. 2009;9:292.

76. Badoual C, Hans S, Rodriguez J, Peyrard S, Klein C, Agueznay $\mathrm{Nel} \mathrm{H}$, et al. Prognostic value of tumor-infiltrating CD4+ T-cell subpopulations in head and neck cancers. Clinical cancer research : an official journal of the American Association for Cancer Research. 2006;12(2):465-72.

77. Tabachnyk M, Distel LV, Buttner M, Grabenbauer GG, Nkenke E, Fietkau R, et al. Radiochemotherapy induces a favourable tumour infiltrating inflammatory cell profile in head and neck cancer. Oral oncology. 2012;48(7):594-601.

78. Zancope E, Costa NL, Junqueira-Kipnis AP, Valadares MC, Silva TA, Leles CR, et al. Differential infiltration of CD8+ and NK cells in lip and oral cavity squamous cell carcinoma. Journal of oral pathology \& medicine : official publication of the International Association of Oral Pathologists and the American Academy of Oral Pathology. 2010;39(2):162-7.

79. Wolf GT, Chepeha DB, Bellile E, Nguyen A, Thomas D, McHugh J, et al. Tumor infiltrating lymphocytes (TIL) and prognosis in oral cavity squamous carcinoma: a preliminary study. Oral oncology. 2015;51(1):90-5.

80. Massano J, Regateiro FS, Januario G, Ferreira A. Oral squamous cell carcinoma: review of prognostic and predictive factors. Oral surgery, oral medicine, oral pathology, oral radiology, and endodontics. 2006;102(1):6776.

81. Oguejiofor K, Hall J, Slater C, Betts G, Hall G, Slevin N, et al. Stromal infiltration of CD8 T cells is associated with improved clinical outcome in HPV-positive oropharyngeal squamous carcinoma. British journal of cancer. 2015;113(6):886-93.

82. Uppaluri R, Dunn GP, Lewis JS, Jr. Focus on TILs: prognostic significance of tumor infiltrating lymphocytes in head and neck cancers. Cancer immunity. 2008;8:16.

83. Moreira G, Fulgencio LB, EF DEM, Leles CR, Batista AC, TA DAS. T regulatory cell markers in oral squamous cell carcinoma: Relationship with survival and tumor aggressiveness. Oncology letters. 2010;1(1):127-32.

84. Annunziato F, Romagnani S. Heterogeneity of human effector CD4+ T cells. Arthritis research \& therapy. 2009;11(6):257.

85. Shang B, Liu Y, Jiang SJ, Liu Y. Prognostic value of tumorinfiltrating FoxP3 + regulatory T cells in cancers: a systematic review and meta-analysis. Scientific reports. 2015;5:15179.

86. Watanabe Y, Katou F, Ohtani H, Nakayama T, Yoshie O, Hashimoto K. Tumor-infiltrating lymphocytes, particularly the balance between $\mathrm{CD} 8(+) \mathrm{T}$ cells and CCR4 $(+)$ regulatory T cells, affect the survival of patients with oral squamous cell carcinoma. Oral surgery, oral medicine, oral pathology, oral radiology, and endodontics. 2010;109(5):744-52.

87. Wansom D, Light E, Thomas D, Worden F, Prince M, Urba $\mathrm{S}$, et al. Infiltrating lymphocytes and human papillomavirus16--associated oropharyngeal cancer. The Laryngoscope. 2012;122(1):121-7.

88. Ward MJ, Thirdborough SM, Mellows T, Riley C, Harris S, Suchak K, et al. Tumour-infiltrating lymphocytes predict for outcome in HPV-positive oropharyngeal cancer. British journal of cancer. 2014;110(2):489-500.

89. Loose D, Signore A, Bonanno E, Vermeersch H, Dierckx R, Deron P, et al. Prognostic value of CD25 expression on lymphocytes and tumor cells in squamous-cell carcinoma of the head and neck. Cancer biotherapy \& radiopharmaceuticals. 2008;23(1):25-33.

90. Erdag G, Schaefer JT, Smolkin ME, Deacon DH, Shea SM, Dengel LT, et al. Immunotype and immunohistologic characteristics of tumor-infiltrating immune cells are associated with clinical outcome in metastatic melanoma. Cancer research. 2012;72(5):1070-80.

91. Nielsen JS, Sahota RA, Milne K, Kost SE, Nesslinger NJ, Watson $\mathrm{PH}$, et al. CD20+ tumor-infiltrating lymphocytes have an atypical CD27- memory phenotype and together with $\mathrm{CD} 8+\mathrm{T}$ cells promote favorable prognosis in ovarian cancer. Clinical cancer research : an official journal of the American Association for Cancer Research. 2012;18(12):3281-92.

92. Shi JY, Gao Q, Wang ZC, Zhou J, Wang XY, Min ZH, et al. Margin-infiltrating CD20(+) B cells display an atypical memory phenotype and correlate with favorable prognosis in hepatocellular carcinoma. Clinical cancer research : an official journal of the American Association for Cancer Research. 2013;19(21):5994-6005.

93. Lao XM, Liang YJ, Su YX, Zhang SE, Zhou XI, Liao GQ. Distribution and significance of interstitial fibrosis and stroma-infiltrating B cells in tongue squamous cell carcinoma. Oncology letters. 2016;11(3):2027-34.

94. Zhou X, Su YX, Lao XM, Liang YJ, Liao GQ. CD19(+)IL$10(+)$ regulatory $B$ cells affect survival of tongue squamous cell carcinoma patients and induce resting CD4(+) T cells to $\mathrm{CD} 4(+)$ Foxp3(+) regulatory $\mathrm{T}$ cells. Oral oncology. 2016;53:27-35

95. Distel LV, Fickenscher R, Dietel K, Hung A, Iro H, Zenk $\mathrm{J}$, et al. Tumour infiltrating lymphocytes in squamous cell carcinoma of the oro- and hypopharynx: prognostic impact may depend on type of treatment and stage of disease. Oral oncology. 2009;45(10):e167-74.

96. Lechner A, Schlosser HA, Thelen M, Wennhold K, Rothschild SI, Gilles R, et al. Tumor-associated B cells and humoral immune response in head and neck squamous cell carcinoma. Oncoimmunology. 2019;8(3):1535293.

97. Rothschild S, Lechner A, Schloesser HA, Thelen M, Shimabukuro-Vornhagen A, Beutner D. Characterization of tumor-associated B cell subsets in head and neck squamous cell carcinoma. American Society of Clinical Oncology;. 2015.

98. Hanna GJ, Liu H, Jones RE, Bacay AF, Lizotte PH, Ivanova 
EV, et al. Defining an inflamed tumor immunophenotype in recurrent, metastatic squamous cell carcinoma of the head and neck. Oral oncology. 2017;67:61-9.

99. Woo SR, Corrales L, Gajewski TF. The STING pathway and the $\mathrm{T}$ cell-inflamed tumor microenvironment. Trends in immunology. 2015;36(4):250-6.

100. Devaud C, John LB, Westwood JA, Darcy PK, Kershaw $\mathrm{MH}$. Immune modulation of the tumor microenvironment for enhancing cancer immunotherapy. Oncoimmunology. 2013;2(8):e25961.

101. Parameswaran J, Burtness B. Immune Checkpoint Inhibition in Cancers that Affect the Head and Neck. International journal of radiation oncology, biology, physics. 2017;98(5):969-73.

102. Merlano M, Occelli M. Review of cetuximab in the treatment of squamous cell carcinoma of the head and neck. Therapeutics and clinical risk management. 2007;3(5):871-6.

103. Hanna GJ, Lizotte P, Cavanaugh M, Kuo FC, Shivdasani $\mathrm{P}$, Frieden A, et al. Frameshift events predict anti-PD-1/L1 response in head and neck cancer. JCI insight. 2018;3(4).

104. Cho J, Johnson DE, Grandis JR. Therapeutic Implications of the Genetic Landscape of Head and Neck Cancer. Seminars in radiation oncology. 2018;28(1):2-11.

\section{(9) 0 ( $)$}

This work is licensed under a Creative Commons AttributionNon Commercial 4.0 International License. 